\title{
The Reform of the Talent Training Model for English Majors Based on OBE
}

\author{
Yuan Zhang* \\ College of Foreign Languages, Inner Mongolia University of Technology, Hohhot 010050, Inner Mongolia Autonomous \\ Region, China \\ *Corresponding author: Yuan Zhang, zhangyuan8283@163.com \\ Copyright: ( 2022 Author(s). This is an open-access article distributed under the terms of the Creative Commons Attribution License (CC \\ BY 4.0), permitting distribution and reproduction in any medium, provided the original work is cited.

\begin{abstract}
Based on the reflection on the traditional teaching model of English majors, this paper points out that language teaching has long been divorced from the cultivation of cultural literacy and social needs; therefore, students' learning initiative has seriously deteriorated. On this basis, this study focuses on the "student-centered" notion and tries to integrate the four functions of language, which include "instrumental," "cognitive," "emotional," and "literacy," to establish a "fourthree-two" teaching model, so as to explore an effective scheme for the teaching reform of English majors.
\end{abstract}

Keywords: Talent training model; English majors; OBE

Online publication: January 20, 2022

\section{Introduction}

The training goal of traditional English majors is to guide students to master several challenging professional skills, such as reading comprehension, grammar, rhetoric, writing, and translation, and skillfully apply these skills to cross-cultural communication activities. Since the Ministry of Education in China has put forward a series of requirements for college education in the new era in 2017, the traditional classroom teaching in colleges has faced difficulty in meeting the needs of English teaching in the new era in terms of teaching philosophy and teaching mode. On the basis of consolidating basic language skills, in order to actively implement the task of "moral education of the youth" in English teaching, realize the "three complete education," which reflects education from various angles, reasonably and effectively alleviate the burden of students, as well as improve students' humanistic quality, educators need to accurately grasp the "pain points" in the teaching practice and solve the existing problems. In the wave of "classroom revolution," it is imperative to have courage to innovate, rethink the teaching concept and teaching mode, as well as truly realize the training goal of teaching and educating English majors in the new era.

\section{Reflection on the "pain points" in traditional teaching}

There are several drawbacks in traditional English classroom teaching, which have restricted the improvement of the teaching effect for a long time.

First, the neglection of the relationship between language and culture causes a lack of perception and understanding of culture and basic humanistic quality among students. 
As an important carrier of culture, language is an important tool to recognize culture, express culture, and carry out intercultural communication. Therefore, the understanding and interpretation of culture is an important basis for language learning. First of all, English learners need to fully understand the traditional Chinese culture and the Chinese socialist culture in the new era. It is necessary for them to assume this as their own cultural position to objectively understand the historical and cultural background of Englishspeaking countries as well as the related cultural elements, such as politics, economy, geography, and literature. Only by standing at the height of equality and the exchange of multi-ethnic cultures as well as constantly improving their cultural understanding and humanistic quality can they correctly understand the language and apply it. This is the key to breaking the surface and deepening the essence of language learning; however, it has been neglected by traditional language teaching.

Second, the "ivory tower" language education is out of touch with social needs. It is said that English majors are "no majors". The unique professional attributes lead to the fact that most English majors would set foot in other industries with English as a tool, such as translation, business, management, international cultural cooperation, as well as scientific and technological exchanges, in addition to directly engaging in English teaching in their future employment. In other words, the social demand for English talents is actually based on skilled English application. Therefore, in order to ensure that students can adapt to the society and are competent for work upon graduation, college English education should not only help students develop excellent comprehensive language application skills, but also pay attention to cultivating compound talents with relevant industry knowledge, speculative ability, research and innovation skills, as well as self-learning ability. However, traditional English teaching often focuses on the training of basic language skills, such as listening, speaking, reading, and writing, and it does not organically combine language learning with social needs, which is unfavorable to students' employment prospects.

Third, the teacher-centered teaching is boring and passive. Traditional English teaching mainly focuses on teachers, whose teaching method is to cram language knowledge into students' brains. As a result, students tend to follow teachers blindly. This method seriously obscures the functions of language learning, such as thinking, cognitive carving, emotional edification, and character cultivation. It also limits the goal of language learning to a lower level of knowledge. It is difficult to stimulate students' interest in language learning, let alone a gain in skill improvement and quality cultivation.

Based on the aforementioned "pain points," beginning with innovating the traditional concept of language teaching and paying more attention to the all-round development of students, the needs of social development and the industry on the basis of extensive criticism and inheritance, this research carries out a reform based on the current situation and future development of students as well as makes positive exploration to cultivate excellent foreign language talents with both morality and ability.

\section{The teaching reform based on OBE}

In 1981, Spady, an American scholar, proposed the concept of outcome-based education (OBE) ${ }^{[1]}$. This concept of education emphasizes the necessity of ability-oriented education and goal-oriented education. Soon, it spread to the United States, Britain, Canada, and other countries and became the mainstream concept of education reform. In recent years, OBE was introduced into China, and this concept has received praised from domestic experts and scholars. Many front-line educators have tried to use it as guidance to carry out their teaching activities, which have achieved good results in varying degrees. Specifically, by reversing the thinking manner, the student-oriented OBE concept is a type of curriculum system construction concept based on results. It breaks the traditional cramming-style teaching method and gives students more freedom and opportunities for their own learning initiatives in learning activities. Evidently, their learning gains are increasing much more than before. 
Under such enlightenment, college English educators have also begun taking OBE as the guiding concept, and a series of reform measures have been carried out. Assuming students as the center, this paper focuses on the integration of the four functions of language, which include "instrumental," "cognitive," "emotional," and "literacy," and establishes the "four-three-two" teaching model to explore the effective reform scheme of undergraduate teaching for English majors.

"Four" refers to the "four-in-one" teaching goal; that is, the pursuit of the achievement of language skills, cognition, emotion, and literacy. In this process, in addition to helping students firmly master basic language elements, such as vocabulary, syntax, text, and rhetoric, as well as the skilled application of basic skills, such as English listening, speaking, reading, writing, and translation, it is also necessary to pay attention to cultivating students' cultural confidence, cultural perception, and understanding ability in the teaching process as well as guide them in the acquisition and exploration of multi-domain knowledge to broaden their horizons, enlighten their minds, sharpen their thinking, improve their taste, enrich their learning, and continuously improve their humanistic quality in this process, so as to enable them to develop a correct outlook on life and world based on language learning. The realization of the "four-in-one" teaching goal emphasizes the flexibility of the realization of one or some of the four goals.

"Three" refers to the trinity teaching process; that is, the combination of pre-class research, in-class learning, and after-class expansion. The "pre-class research" stage refers to the period before starting a new content of a unit. In this stage, teachers have the responsibility to design research questions pertaining to relevant contents and send them to their students in advance through e-learning platforms, such as MOOC, Smart Tree, etc. Students then use various media resources, such as the network, library, and mobile applications, to conduct exploratory research and group discussions based on their previous achievements. On this basis, they can use of various approaches, such as PowerPoint slides, research practice reports, etc., to share their views as a group about the problems raised by the teacher prior to class and raise questions pertaining to the discussion topic.

In the "in-class learning" stage, it is a norm for students to present the research content and results as well as put forward questions in the form of group reports or PowerPoint slides. The teacher and the students would then discuss on the topic, and the teacher would finally summarize and provide brief comments. From there, the class moves on to learning the main content. With the help from the teacher, the students thoroughly study the text background, key and difficult words or sentences, discourse characteristics, rhetorical devices, after-school exercises, and even humanistic knowledge through detailed analysis to understand and master the contents. The whole learning process in class is dominated by students; teachers, on the other hand, play the role of organizers, promoters, and motivators. They provide the finishing touch by emphasizing on the key points, difficulties, and sublimation points of knowledge.

The "after-class expansion" stage is based on the exploration and extension of cultural knowledge, related disciplines, and humanistic knowledge points involved in the teaching content of each unit. This stage aims to sublimate students' thoughts, stimulate their interest in learning, and promote them to consolidate the knowledge and skills which they have learned in a particular unit. After-class expansion, including curricular activities and extracurricular activities, is carried out after completing the basic teaching content of a unit. Extracurricular activities include research, vlog recording, film reviews, book reviews, translation, and translation appreciation on online learning platforms, while curricular activities include reports, discussions, comments, and other forms.

"Two" refers to the dual teaching evaluation; that is, the combination of summative evaluation and developmental evaluation. The former refers to evaluating students' academic performance in the form of traditional mid-term and final exams as well as in-class tests, whereas the latter refers to tracking students' specific learning performance in daily learning. The reason for this evaluation is in view of the difficulty in determining the problems in the process of teaching by simple summative evaluations, and thus it is 
impossible to make a valuable analysis of students' development. Therefore, summative evaluation is combined with developmental evaluation. In addition to using conventional evaluation means, such as unit, mid-term, final, and professional examinations, to evaluate students' learning effect, self-evaluation forms, group evaluation forms, teacher evaluation forms, assistant teacher evaluation forms, social activity participation evaluation forms, competition award tables, and other multi-agent measurement tools have been designed to comprehensively collect students' daily learning information inside and outside the course, classroom, and at all stages of the teaching and learning process in a timely manner, so as to establish personal learning files. At the end of the semester or the academic year, based on the weightage of the four summary evaluations and six developmental evaluations, the teachers would make a comprehensive, dynamic, and multi-dimensional evaluation for each student's academic performance throughout the semester or academic year.

The dual teaching evaluation form does not only comprehensively and objectively evaluate students, taking into account their knowledge mastery, skill formation, emotional change, character development, and other dimensions, but also provide valuable feedback for teachers to review their own teaching gains and losses as well as improve their teaching methods.

For the smooth implementation of the "four-three-two" teaching model, four points should be emphasized: (1) the leading role of students in the links before, during, and after class; the emphasis on students' autonomy, practicality, participation, and experience in the whole learning process; (2) the focus on classroom teaching in the whole teaching process as well as the extension and expansion in time, space, and content, which may happen before class, in class, or after class, using textbooks, network-library information, audio media, videos, etc.; (3) considering students as the main body in each teaching stage, relying on the progressive realization of knowledge objectives, ability objectives, and literacy objectives, as well as enriching learning activities, such as speculation, discussion, reading reports, research statement, theme interviews, impromptu speeches, and courseware production; (4) the focus on students' profound, enlightening, and touching personal practice and experience when going through each teaching stage based on the first three points.

\section{Evaluation of the teaching effect based on OBE}

Advanced English is an essential basic course for senior English majors ${ }^{[2]}$. It aims to improve students' comprehensive language application skills and guide students to think deeply about the theme of the text, so as to improve their humanistic quality. In fact, the cultivation of students' language knowledge ability

and the improvement of their comprehensive skills would eventually be merged with the improvement of their humanistic quality. The repeated training of these three levels and the realization of these skills layer by layer run through the learning of each unit. There are 10 units in Advanced English. The corresponding relationship between the specific content of each unit and the perspective of humanistic quality training is shown in Table 1. 
Table 1. Relationship between the specific content of each unit and the perspective of humanistic quality training

\begin{tabular}{|c|c|}
\hline Unit & Humanistic quality training \\
\hline $\begin{array}{l}\text { Unit 1. Face to Face with Hurricane } \\
\qquad \text { (Volume 1) }\end{array}$ & ourage; love and responsibility in the face of disaster or crisis. \\
\hline $\begin{array}{l}\text { Unit 2. Hiroshima - The "Liveliest City } \\
\text { in Japan" (Volume 1) }\end{array}$ & $\begin{array}{l}\text { Remembering history and cherishing peace; dialectical thinking on the atomic } \\
\text { bombing of Japan. }\end{array}$ \\
\hline $\begin{array}{l}\text { Unit 4. The Trial That Rocked the World } \\
\qquad \text { (Volume 1) }\end{array}$ & $\begin{array}{l}\text { Critical thinking of the Bible; establishing scientific thoughts and advocating a } \\
\text { scientific spirit. }\end{array}$ \\
\hline Unit 12. Ships in the Desert (Volume 1) & Ecological civilization view. \\
\hline $\begin{array}{l}\text { Unit 14. Speech on Hitler and the } \\
\text { Invasion of the U.S.S.R (Volume 1) }\end{array}$ & $\begin{array}{l}\text { Reflection on the war; the fragility of human civilization; the importance of } \\
\text { building a community with a shared future for mankind. }\end{array}$ \\
\hline Unit 3. Inaugural Address (Volume 2) & $\begin{array}{l}\text { Dialectical thinking on American value management; establishing the cultural } \\
\text { self-confidence of the nation. }\end{array}$ \\
\hline Unit 4. Love is a Fallacy (Volume 2) & Establishing a correct view on love. \\
\hline Unit 5. Sad Young Men (Volume 2) & $\begin{array}{l}\text { Thinking about the troubles in the process of growth; establishing a correct sense } \\
\text { of social responsibility. }\end{array}$ \\
\hline $\begin{array}{l}\text { Unit 13. The Mansion: A Subprime } \\
\text { Parable (Volume 2) }\end{array}$ & $\begin{array}{l}\text { Understanding the composition of American social stratum pyramid; } \\
\text { understanding the false interpretation of "equality" in the American society. }\end{array}$ \\
\hline Unit 14. Faustian Economics (Volume 2) & $\begin{array}{l}\text { Correctly understanding the important value of "four self-confidence" and the } \\
\text { connotation of socialism with Chinese characteristics by understanding the } \\
\text { essence of the American economic development model. }\end{array}$ \\
\hline
\end{tabular}

Integrating humanistic education into curriculum teaching naturally runs through the three stages of students' autonomous learning process - "before-class," "during-class," and "after-class." It is also being paid special attention to in the evaluation system before and after class. Practice has proven that this approach has achieved good results. Taking Unit 14 (Volume 1) as an example, which discusses about Churchill's famous speech on World War II, this research shows the implementation and teaching effect of the "four-three-two" teaching model under the OBE concept.

In the "pre-class research" stage, upon uploading the Second Waltz composed by a former Soviet composer, Shostakovich, on the MOOC platform, the students are requested to appreciate the waltz in groups. In this way, the teacher naturally introduces the topic on World War II to the students. On that basis, the students are then required to consult the background of World War II and preview the text to understand the main idea. Sensory experience can easily arouse students' interest; therefore, the learning of this unit can be initiated through the appreciation of classical music with a strong sense of rhythm and story plot, which can effectively steer students in the direction of knowledge learning. In terms of practical effect, students' investment ratio would be higher.

In the "in-class learning" stage, students are invited to share their understanding of this waltz through group presentations as well as extend their learning enthusiasm and desire to share with the classroom. On the basis of understanding the background of the text, the students are asked to share their feelings from the image created in their minds when listening to the music. The teacher then guides the students to discuss about the war from the perspective of German Nazis attacking the Soviet Union. Thereafter, the students are steered into learning the language points. Focusing on the "disaster brought by the war to the people of Soviet Union" and the "cruelty of the Nazis" as starting points, the teacher then asks the students to read the text quickly and look for the adjectives and verbs under the above two categories, respectively. The 
students are then given two tasks: the first is to connect the keywords to their interpretations, and the second is to make sentences with those keywords. The students are required to complete the tasks in pairs and mark out the words that they do not understand. The teacher then provides the solution to those unresolved problems.

In this stage, the students are guided to look for the knowledge points and the problems in the output process. The students are driven to solve the problems with the help of the evaluation and explanation from the teacher. The students are then required to work in pairs to complete the paraphrase in English and construct English-Chinese translations for those sentences and texts containing the above keywords through mutual aid. Thereafter, the teacher corrects the errors and evaluates the effect of the group presentation to help the students gain an in-depth understanding and accurate application of those words describing the war as well as the key contents of the text.

Based on the understanding of the background knowledge and the mastery of language points, the students then move on to the "after-class expansion" stage. The teacher uploads the task on the MOOC platform and asks the students to group up alike the "pre-class research" stage to discuss around the keywords, such as "war," "disaster," and "human civilization," in combination with relevant online materials, such as "the importance and necessity of establishing a community of human destiny." In this stage, students should pay attention to the use of vocabulary learned during class and the expansion of relevant vocabulary outside class.

In the teaching cycle, the whole process is student-centered. Through production-oriented teaching ${ }^{[3]}$, experiential teaching ${ }^{[4]}$, task-driven teaching ${ }^{[5]}$, mutual aid teaching ${ }^{[6]}$, and other teaching methods and means, the teaching cycle has well-stimulated students' interest in learning and their enthusiasm for active learning in addition to achieving good teaching results. In the group discussion before and after class, 40 students are divided into 8 groups, comprising of 5 students in each group. According to the records, each group spoke more than 25 times, and each person spoke at least 5 times; the repetition rate of views was not higher than $6 \%$, indicating that the students showed high enthusiasm and active participation. In addition, as far as the mastery of language points is concerned, a total of 20 words were included, of which the correct rate of connecting words with word meaning was $80 \%$, the correct rate of sentence making was $60 \%$ (before explanation), and the correct rate of paraphrase as well as translation of sentences and texts was $75 \%$ (after explanation). It can be appreciated that the students' autonomous learning effect is good.

Based on the exploration of more effective teaching reform of Advanced English, the achievements of other course groups have been taken into consideration, and this teaching model has been applied in the teaching of other professional courses in every grade of English majors, so as to strengthen the cultivation of multi-level ability and the improvement of humanistic quality on the basis of improving students' comprehensive skills. The result of this research would help students better adapt to the society and freely realize cross-cultural communication in the context of globalization.

\section{Disclosure statement}

The author declares that there is no conflict of interest.

\section{References}

[1] Yu S, 2020, Specialty and Curriculum Construction Based on OBE Education Concept, Intellectual Property Press, Beijing.

[2] Zhang H, 2017, Advanced English, Foreign language teaching and Research Press, Beijing.

[3] Wen Q, Sun S, 2020, Designing Scenarios for the Motivating Phase in the Production-Oriented Approach: Key Elements and Examples. Foreign Language Education in China, 2020(2): 4-11, 90. 
[4] Feng M, 2019, Experiential Teaching in College English Intensive Reading. Journal of the Chinese Society of Education, 2019(11): 112.

[5] Zeng Y, 2020, Teaching Practice of Task Driven Cooperative Learning in the Context of Academic English Listening and Speaking Teaching. College Foreign Language Teaching \& Research, 2020(1): 147-159, 186-187.

[6] Wei H, Chen J, 2016, A Study on College Students' Participation in English Classroom Under "PeerInstruction" Model. Modern Communication, 2016(4): 201-202.

\section{Publisher's note}

Bio-Byword Scientific Publishing remains neutral with regard to jurisdictional claims in published maps and institutional affiliations. 